\title{
Movements and diet of crested porcupines in the Maremma Natural Park, central Italy
}

\author{
Giorgio PIGOZZI and Ian J. PATTERSON
}

Pigozzi G., and Patterson I. J. 1990. Movements and diet of crested porcupines in the Maremma Natural Park, central Italy. Acta theriol. 35: 173-180.

Data from capture-recapture, radio-telemetry and recovery of marked quills were used to investigate movements of crested porcupines Hystrix cristata Linnaeus, 1758, in a Mediterranean coastal habitat in central Italy. Mean distance moved between successive captures was similar in males and females $(p>0.10)$. Distances moved by crested porcupines in the pinewood proved significantly greater than those in the grazing areas $(p<0.05)$. Radio-tracking data and night observations indicated that porcupines living in the grazing areas moved towards agricultural fields located at a distance of about $2 \mathrm{~km}$. Conversely, no porcupines living in the pinewood were observed in the agricultural fields although they made longer movements, reaching foraging places at a distance of up to $4.4 \mathrm{~km}$. Faecal analysis showed spatial differences in the summer diet, with crops being found almost exclusively in droppings collected in the grazing areas closer to agricultural fields. Managements implications of these results are discussed.

Via S. Sofia 188, 21040 Cislago, Varese, Italy, (GP); University of Aberdeen, Department of Zoology, Culterty Field Station, Newburgh, Aberdeenshire AB4 0AA, Scotland (IJP)

Key words: movements, diet, Hystrix cristata, Italy

\section{Introduction}

In recent years crested porcupines Hystrix cristata have significantly extended their range northward and eastward in Italy (Tomei and Cavalli 1976, Santini 1980, Pandolfi 1986, Sala 1987) but information on their feeding ecology is rather scanty. In the northern part of Tuscany, central Italy, the diet of crested porcupine consists primarily of hypogeal parts of several wild plants and the seeds and fruits of cultivated plants (Santini 1980, 1983). Crested porcupines visit feeding areas as far as $10-12 \mathrm{~km}$ from their dens, and, in the littoral hills of south Tuscany, they probably carry out an even longer distance seasonal movement in, search for food and more hospitable environments (Santini 1980).

In this paper we present preliminary data on the movements and diet of crested porcupines in the Maremma Natural Park, collected primarily during the summer season when crop production is generally at its peak.

\section{Study area}

The study was conducted in the inner part of the Maremma Natural Park, central Italy $\left(42^{\circ} 39^{\prime} \mathrm{N}\right.$, $11^{\circ} 05^{\prime} \mathrm{E}$ ), beside the Tyrrhenian coast. The vegetation pattern within the study area is heterogeneous with 


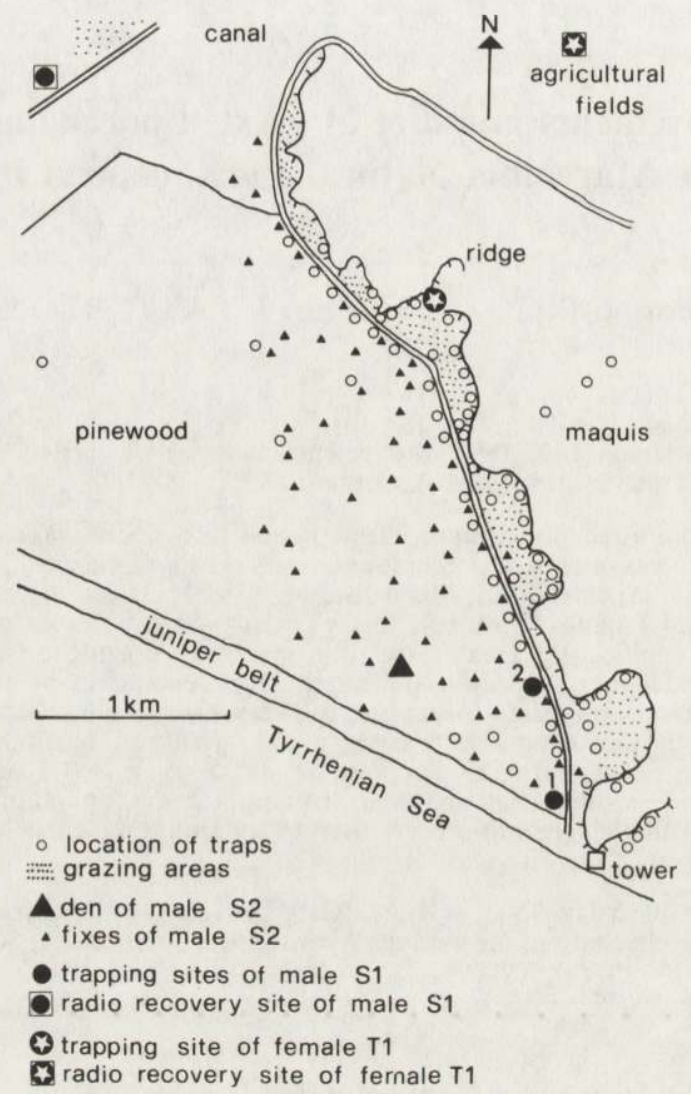

Fig. 1. Study area in the inner part of the Maremma Natural Park, central Italy; the locations of both trapping and radio-recovery sites of $\mathrm{S} 1$ and $\mathrm{T} 1$ as well as radio-fixes of $\mathrm{S} 2$ are shown.

two principal communities represented. The dominant association is the pinewood forest (Pinus pinea and Pinus pinaster), which occurs below a limestone ridge (part of the Uccellina Mounts, $417 \mathrm{~m}$ a.s.1.) and ends near the shore with a high density belt of junipers Juniperus oxycedrus macrocarpa. The mediterranean maquis habitat is found above the limestone ridge and is dominated by oaks (Quercus ilex, Quercus cerris). An artificial canal and a few grazing areas, used by large herbivores (i.e. fallow-deer Dama dama, roe-deer Capreolus capreolus, wild boar Sus scrofa), divide the main pinewood habitat from the limestone ridge and the maquis (Fig. 1). Human interference in the study area is negligible but there are a few agricultural fields about $2 \mathrm{~km}$ from the study site. Detailed vegetational descriptions of the inner part of the Maremma Natural Park are available elsewhere (Arrigoni et al. 1976).

\section{Material and methods}

\section{Capture}

Crested porcupines were captured in large cage traps of welded steel mesh with a single gate and a monofilament nylon string as a trigger mechanism (Pigozzi 1988a). When the string was disturbed by the animal eating the bait, a pin was pulled allowing the gate to drop. The bait (peanuts and occasionally maize) 
was distributed around the trap but was more abundant below the nylon string. Traps were never specifically set to capture crested porcupines, being instead deployed in places which enhanced the likelihood of capturing badgers Meles meles, the main object of study. Trapping periods usually lasted a week and were repeated every month between September 1983 and November 1985. Traps were checked daily, usually in the early morning, and captured individuals were immobilized with intramuscular injections of xylazine hydrochloride and ketamine hydrochloride (Pigozzi 1987a). They were weighed, sexed and measured (Pigozzi 1987b) and then marked individually with coloured-numbered ear-tags and plastic-coloured tapes around several quills of the dorsal area (Pigozzi 1988b).

Movements

Three individuals were fitted with 151 or $173 \mathrm{MHz}$ radio-transmitters, one with a radio-collar (Custom Electronics, Urbana, USA) and the remaining with a small radio-package attached to five thicker contiguous quills of the dorsal area. Movement data were collected telemetrically using a 12-channel receiver (AVM, Champaign, USA) and either a 3-elements Yagi aerial or a non-directional dipole aerial (Parish 1980). Under line-of-sight conditions radio signals were audible at $2-3 \mathrm{~km}$ but their actual range varied greatly owing to the presence of the limestone ridge and the dense vegetation cover. Radio-fixes were determined by triangulation of a minimum of two compass bearings taken from tracking stations established within the study area. Often only two bearings were used to plot a radio-fix, especially when a crested porcupine was moving rapidly. By the time a third tracking station was reached, the rapidly moving animal could be far from the area where the first bearing had been recorded. In these cases a third bearing was primarily used as a useful check on the direction of the animal's movement. Locations were plotted on standard 1: 5,000 topographic maps. The accuracy of the radio-tracking technique was estimated to be $\pm 5^{\circ}$ through placement and subsequent relocations of transmitters in the field. Generally only one fix per animal was taken each day. Most relocations were obtained at night mainly between 18.00 and 06.00 GMT to discover which areas were used by crested porcupines during their activity periods. However, some day time fixes were also taken to learn more about the den locations. Crested porcupine activity was determined by holding the aerial steady at one position for $60 \mathrm{sec}$. (instantaneous time-sampling, sensu Jacobsen and Wiggins 1982) and noting any variations in signal intensity.

Perceived daily movements (sensu Laundré et al. 1987) of crested porcupines were determined by measuring the straight-line distance between subsequent relocations of radio-tagged and quill-marked individuals from successive nights. In addition to radio-tracking data, further indications on the movements of crested porcupines were obtained by combining capture-recapture information with data derived from the recovery of marked quills. Finally, during the week around full moon crested porcupines were observed at night through an image intensifier (Aeritalia, Milano, Italy) and were also followed during their feeding forays.

Differences between the sexes in the distances moved were analysed by the Mann-Whitney U-test. All tests were two-tailed unless otherwise stated.

\section{Diet}

Droppings were collected in July 1984 from the north-east slope of the limestone ridge, from the base of the cliffs on its south-wets edge, from the pinewood east of Torre Collelungo and from the main pinewood area (Fig. 1). The samples were dried for storage and were analyzed by dispersing the material in $70 \%$ alcohol and examining the fragments under a dissecting microscope. For the purpose of this study we used anatomical structures of the food items, especially crops, that resist digestion and can be readily recognized in the faeces. These recognition fragments were used to allocate all of the faecal contents from the particular species of crop found in the faeces. Their use obviates the need to perform sophisticated microhistological examinations (cf. Sparks and Malecheck, 1968) to identify epidermal and cell characteristics of each botanical species in the droppings. Analysis of faeces revealed identifiable fragments from grain husks and sunflower seed husks, the two most common crops cultivated in the agricultural fields near the study area. 
Accordingly, dietary information was summarized into three main categories: grain husks, sunflower seed husks and other plant materials (e.g. underground storage organs, grass).

\section{Results and discussion}

Movements

Patterns in perceived daily movements made by crested porcupines over a two-year period have been investigated by different statistical techniques using data from September 1983 to November 1985. Mean distances moved between successive captures, occurring within the same trapping session, are given in Table 1. Distances ranged between $0 \mathrm{~m}$ (individual recaptured in the same location on a subsequent night)

Table 1. Distance moved $(\mathrm{m}) \overline{\mathrm{x}} \pm \mathrm{SE}$, with range of values in parenthesis and sample size, between successive captures of crested porcupines in two habitats of the Maremma Natural Park during the period from September 1983 to November 1985.

\begin{tabular}{cccccc}
\hline & \multicolumn{2}{c}{ Pinewood } & & \multicolumn{2}{c}{ Grazing areas } \\
\cline { 2 - 3 } \cline { 5 - 6 } & Male & Female & & Male & Female \\
\hline $\bar{x} \pm$ SE & $746 \pm 186.0$ & $460 \pm 157.2$ & & $225 \pm 47.0$ & $210 \pm 51.4$ \\
Range & $(180-1300)$ & $(50-1100)$ & & $(0-500)$ & $(0-750)$ \\
$N$ & 5 & 7 & & 10 & 14 \\
\hline
\end{tabular}

and $1300 \mathrm{~m}$. Distances moved by males and females were not significantly different in either the pinewood $(\mathrm{U}=10, p>0.05)$ or the grazing areas $(\mathrm{U}=62, p>0.10)$. After combining data from males and females in each habitat, the distance moved by crested porcupines in the pinewood proved significantly greater than that in the grazing areas $(z=-2.18, p<0.05)$. Such a difference was primarily due to male movements $(\mathrm{U}=6$,

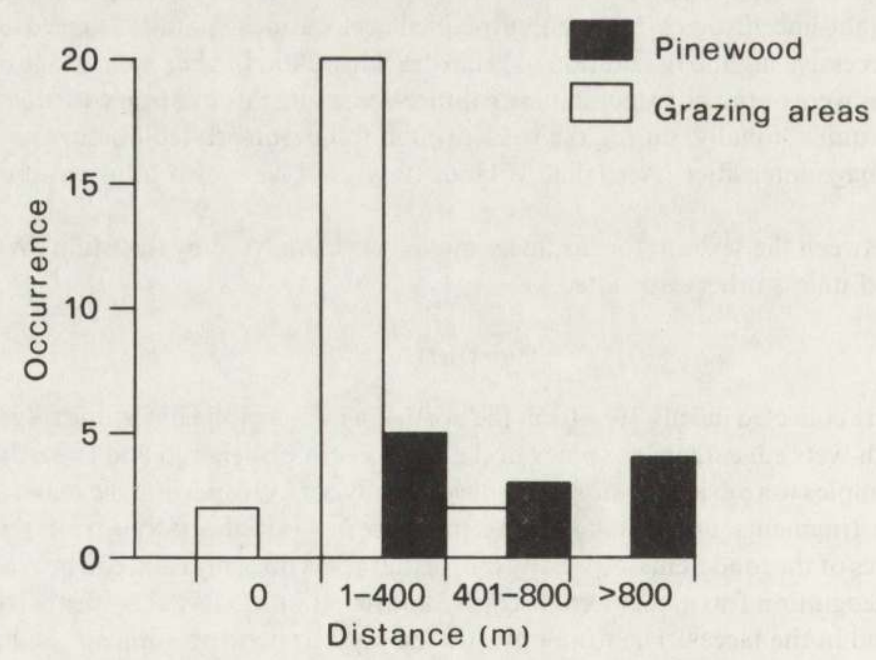

Fig. 2. Distances $(\mathrm{m})$ between successive captures of crested porcupines in two habitats of the Maremma Natural Park. 
Table 2. Distances $(m) \bar{x}+S E$, with range of values in parenthesis, between the location of fixes and the male's den during the period between May and September 1985.

\begin{tabular}{lcc}
\hline Month & $\begin{array}{c}\text { Number } \\
\text { of fixes }\end{array}$ & Distance (m) \\
\hline May & 13 & $\begin{array}{c}792 \pm 80.0 \\
(300-1200)\end{array}$ \\
June & 17 & $\begin{array}{c}1012 \pm 161.3 \\
(200-2600)\end{array}$ \\
July & 9 & $\begin{array}{c}1022 \pm 172.2 \\
(300-1300)\end{array}$ \\
August & 18 & $\begin{array}{c}1294 \pm 189.1 \\
(200-2800)\end{array}$ \\
September & 8 & $\begin{array}{c}1043 \pm 187.2 \\
(450-1750)\end{array}$ \\
\hline
\end{tabular}

$p<0.05$ ), as the distance moved by females was not significantly different in the two habitats $(\mathrm{U}=35, p>0.10)$. In addition Fig. 2 shows that long-distance movements (i.e. $>800 \mathrm{~m}$ ) were more likely to occur in the pinewood $(33.3 \%)$ than in the grazing areas $(0 \%)$ (Fisher's exact test, $p=0.016)$. On eight occasions we found marked quills shed by porcupines which had been previously captured (fewer than six days earlier, i.e. during the trapping session of that month) in the grazing areas. The distance between the location of capture and the sites where marked quills were recovered was similar for males $(\bar{x}=607 \mathrm{~m}, \mathrm{n}=4)$ and females $(\bar{x}=975 \mathrm{~m}$, $n=4)$. One could argue that these results might be affected by the locations where traps were placed, as they were often deployed near badger setts. However, this was unlikely to be a serious shortcoming, since crested porcupines occupy setts simultaneously used by badgers (Pigozzi 1986).

Of the three individuals radio-tracked during this study, two (male S1 and female T1) lost their radio-transmitter within three days from their capture. The female, captured in the grazing areas on $5 / 7 / 1984$, moved to the agricultural fields above the limestone ridge and lost the radio-transmitter in a sunflower field $1.6 \mathrm{~km}$ from the site of capture. The male, captured in the pinewood near Torre Collelungo on 14/7/1984, lost the radio-package on the opposite side of a canal which divided the border of the northernmost edge of the pinewood from a few grazing areas. The juniper belt where the animal was captured was at a straight-line distance of approximately $4.4 \mathrm{~km}$ from the site of the radio-transmitter recovery. Thus, the porcupine must have traversed the entire pinewood and then crossed the $8 \mathrm{~m}$ wide canal by swimming. It seems reasonable to believe that the efforts made by the porcupine to get rid of the water, after reaching the opposite side of the canal, could be responsible for the shedding of the quills to which the radio-package was attached. Unfortunately, no attempts could be made to find either the den or the area in which this porcupine was resident. This individual was recaptured, in good physical conditions, about five months later $(4 / 12 / 1984)$ in the pinewood, at a distance of $500 \mathrm{~m}$ from the location where it had been previously trapped. This finding suggests that the porcupine did not seriously suffer from the application of the radio-package; furthermore, should the den be located in the canal area, it would also suggest that the extensive movement made by the male after being radio-tagged was not exceptional and could be repeated. As the distances moved by the radio-collared male also included several extensive movements (cf. Table 3), one might wonder whether such movements play an important role in the pattern of use of space in the pinewood. 
Table 3. Contents of crested porcupine droppings $(n=49)$ collected in different areas of the Maremma Natural Park during July 1984.

\begin{tabular}{lcccc}
\hline \multirow{2}{*}{ Habitat } & \multicolumn{4}{c}{ Number of droppings containing: } \\
\cline { 2 - 5 } & Grain & Sunflower & $\begin{array}{c}\text { Grain and } \\
\text { sunflower }\end{array}$ & $\begin{array}{c}\text { Other plant } \\
\text { material }\end{array}$ \\
\hline Ridge: NE side & 3 & 7 & 2 & 0 \\
Ridge: cliff & 3 & 14 & 2 & 2 \\
Pinewood: S-tower & 0 & 0 & 1 & 5 \\
Pinewood & 0 & 0 & 0 & 10 \\
\hline
\end{tabular}

A total of 73 night fixes were taken on radio-collared male S2 between May and September 1985. Overall the animal was active in $89 \%$ of the night fixes. Both nocturnal and diurnal fixes, taken while the animal was not active (and not included in the following analyses), indicated that the male was using a single den in the pinewood which was located about $300 \mathrm{~m}$ from the juniper belt. It seems therefore reasonable to compare the distances between the location of fixes and the animal's den (Table 2). During August the porcupine performed extensive movements which proved significantly greater than those observed in any other month of this study (Mann-Whitney test, $p<0.05$ in all cases). Although the movements made in May appeared comparatively smaller than those in June, July and September, the observed differences were not statistically significant ( $p>0.1$ in all cases). These distances were comparatively greater than those reported for Indian crested porcupines living in the Negev desert (Saltz and Alkon 1989); nevertheless in both studies these distances tended to increase from early to late summer. However, the results of this study should be interpreted with caution as the values reported in Table 2 refer to straight-line distances between two locations. Porcupines in contrast did not move in straight lines, when observed through the image intensifier, but tended to follow the edges of the vegetation cover, presumably avoiding unnecessary movements in open fields. This tendency was more pronounced during nights of full-moon, which is in agreement with data on the activity pattern and movements of Indian crested porcupines (Alkon and Saltz 1988, Saltz and Alkon 1989). Thus, real distances moved by porcupines on a nightly basis could be several times greater than the distances reported in Table 2.

\section{Diet}

Most of the droppings collected from the limestone ridge contained sunflower or grain husks, or even both of those in the same droppings (Table 3 ). This was especially true for droppings from the north-east side of the ridge which all contained one or both of these crops. In contrast, none of the droppings from the main pinewood area contained grain or sunflower and only one dropping from the small sample taken east of Torre Collelungo did so (Table 3). As a result, the occurrence of crops in the droppings proved significantly greater at the base and above the limestone ridge $(93.9 \%, 31 / 33)$ than in the pinewood areas $(6.2 \%, 1 / 16)\left(\chi_{\mathrm{c}}^{2}=32.8, p<0.001\right)$. Thus, 
crop remains occurred in droppings collected up to $2 \mathrm{~km}$ from the agricultural fields but were not found in those from more distant parts especially on the opposite side of the canal. This result is not surprising since on no occasions were the two males from the pinewood found above the limestone ridge in the maquis or, more importantly, in the agricultural fields.

\section{Management implications}

The results of this preliminary investigation suggest that porcupines consuming exclusively natural foods in the pinewood made long-distance movements probably in search for food. Although few data on the movement patterns of porcupines (e.g. female T1) living closer to agricultural fields are available, both radio-tracking and dietary information indicate the exploitation of crops during the summer period. The degree of damage to agricultural production varied from slight to substantial depending on the type of crop and the location of the field attacked by crested porcupines. For example, overall damage by crested porcupines to sunflower and grain seemed to be generally slight, being more pronounced in the field margins and, particularly, in those sides of the perimeter which were closer to tree cover. This finding is in agreement with previous reports regarding damage to potato crops by the Indian crested porcupine in the Negev desert (Alkon and Saltz 1985a, b). Yet, substantial damage could be caused to intensive cultivation of water melon. In this case crested porcupines could typically give one or two bites to a water melon and then move to the next one, a process which could be repeated dozens of times during the course of a single night with no apparent preference for fruits located at the periphery (G. Pigozzi, unpubl.). Local farmers maintain that repeated damage to water melon crops, on exactly the same place at interval of days, may be attributable to specific individual(s), as the selective removal of the damaging animal(s) removes the problem. Water melons generally occur in open fields away from tree cover so that crested porcupines have to make exposed long-distance movements that involve high search costs including increased predation risks (sensu Westoby, 1978). As this foraging decision is likely to be taken by few individuals, due to the predatory-sensitive behaviour exhibited by porcupines (Alkon and Saltz 1985b, 1988), we recommend the use of artificial low-intensity illumination at the periphery of fields. This passive approach should be effective in reducing damage (as shown by Alkon and Saltz 1985b), and, more importantly, be respectful of the law which sanctioned the protection of this species on the Italian territory in 1974.

Acknowledgements: We are grateful to I. Boschi and P. Tonelli for technical and logistical support. The image intensifier and most of the radio-tracking equipment were provided through a research grant to $\mathrm{S}$. Lovari. We thank M. Olgiati for translating several German papers and M. Calisti and S. Lovari for field assistance. G.P. was supported by a research grant from the Italian Ministry of Education (M.P.I.) and I.J.P. was supported by a grant from the Royal Society-Accademia Nazionale dei Lincei, The Carnegie Trust and Aberdeen University, which are gratefully acknowledged. 


\section{References}

Alkon P. U. and Saltz D. 1985a. Potatoes and the nutritional ecology of crested porcupine in a desert biome. J. Appl. Ecol. 22: $727-737$.

Alkon P. U. and Saltz D. 1985b. Patterns of crested porcupine (Hystrix indica) damage to cultivated potatoes. Agric. Ecosystems Environ. 14: 171-183.

Alkon P. U. and Saltz D. 1988. Influence of season and moonlight on temporal-activity patterns of Indian crested porcupines (Hystrix indica). J. Mammal. 69: 71-80.

Arrigoni P. V., Gellini R., Innamorati M., Lenzi Grillini C., Lovari A., Piussi P., Renzoni A., Sanesi G. and Sartoni G. 1976. Relazione al Consorzio per l'istituzione del Parco della Maremma. Inform. Bot. Ital. 8: $283-324$.

Jacobsen N. and Wiggins A. D. 1982. Temporal and procedural influences on activity estimated by time-sampling. J. Wildl. Manage. 46: 313-324.

Laundré J. W., Reynolds T. D., Knick S. T. and Ball I. J. 1987. Accuracy of daily point relocations in assessing real movement of radio-marked animals. J. Wildl. Manage. 51: 937-940.

Pandolfi M. 1986. Modificazioni recenti nell'areale di Hystrix cristata Linnaeus, 1758, nell' Italia centrale adriatica. Hystrix 1: 69-76.

Parish T. 1980. A collapsible dipole antenna for radio-tracking on $102 \mathrm{MHz}$. [In: A handbook on biotelemetry and radio tracking . C. J. Amlaner and D. W. Macdonald, eds] Pergamon Press, Oxford: $263-268$.

Pigozzi G. 1986. Crested porcupines Hystrix cristata within badger setts Meles meles in the Maremma Natural Park, Italy. Säugetierk. Mitt. 33: 261-263.

Pigozzi G. 1987a. Immobilization of crested porcupines with xylazine hydrochloride and ketamine hydrochloride. J. Wildl. Manage. 51: 121-123.

Pigozzi G. 1987b. Female-biased sexual size dimorphism in the crested porcupine (Hystrix cristata L.). Boll. Zool. 54. 255-259.

Pigozzi G. 1988a. The capture and immobilization of the European badger, Meles meles (L.), in its natural environment. Atti Soc. ital. Sci. nat. Museo civ. Stor. nat. Milano 129: 56-70.

Pigozzi G. 1988b. Quill-marking, a method to identify crested porcupines individually. Acta theriol. 33: $138-142$.

Sala L. 1987. Prima segnalazione di istrice, Hystrix cristata L., in provincia di Modena. Atti Soc. ital. Sci. nat. Museo civ. Stor. nat. Milano 128: 203-206.

Saltz D. and Alkon P. U. 1989. On the spatial behaviour of Indian crested porcupines (Hystrix indica). J. Zool., Lond. 217: 255-266.

Santini L. 1980. The habits and influence on the environment of the Old World porcupine Hystrix cristata L. in the northernmost part of its range. Proc. 9th Vertebrate Pest Conference: 149-153.

Santini L. 1983. I roditori italiani di interesse agrario e forestale. Consiglio Nazionale delle Ricerche AQ/1/232: $117-122$.

Sparks D. R. and Malecheck J. C. 1968. Estimating percentage dry weight in diets using a microscopic technique. J. Range. Manage. 21: 264-265.

Tomei P. E. and Cavalli S. 1976. L'areale dell'istrice (Hystrix cristata L.) a Nord dell'Arno. Atti Soc. Tosc. Sc. Nat., Mem. ser. B 83: $42-48$.

Westoby M. 1978. What are the biological bases of varied diets? Am. Nat. 112: 627-631.

Received 20 October 1989, accepted 20 July 1990. 